Article

\title{
Protocol to Manage Heritage-Building Interventions Using Heritage Building Information Modelling (HBIM)
}

\author{
Isabel Jordan-Palomar ${ }^{1, *}$, Patricia Tzortzopoulos ${ }^{2} \mathbb{E}^{\mathbb{E}}$, Jorge García-Valldecabres ${ }^{3}$ and \\ Eugenio Pellicer ${ }^{4}$ \\ 1 Instituto de Restauración del Patrimonio, Universitat Politècnica de València, 46022 Valencia, Spain \\ 2 School of Art, Design and Architecture, University of Huddersfield, Huddersfield HD1 3DH, UK; \\ p.tzortzopoulos@hud.ac.uk \\ 3 Graphic Expression Department, Universitat Politècnica de València, 46022 Valencia, Spain; \\ jorgegvallde@gmail.com \\ 4 School of Civil Engineering, Universitat Politècnica de València, 46022 Valencia, Spain; pellicer@upv.es \\ * Correspondence: isjorpa@upvnet.upv.es; Tel.: +34-616-540-497
}

Received: 31 January 2018; Accepted: 15 March 2018; Published: 21 March 2018

\begin{abstract}
The workflow in historic architecture projects presents problems related to the lack of clarity of processes, dispersion of information and the use of outdated tools. Different heritage organisations have showed interest in innovative methods to resolve those problems and improve cultural tourism for sustainable economic development. Building Information Modelling (BIM) has emerged as a suitable computerised system for improving heritage management. Its application to historic buildings is named Historic BIM (HBIM). HBIM literature highlights the need for further research in terms of the overall processes of heritage projects, its practical implementation and a need for better cultural documentation. This work uses Design Science Research to develop a protocol to improve the workflow in heritage interdisciplinary projects. Research techniques used include documentary analysis, semi-structured interviews and focus groups. HBIM is proposed as a virtual model that will hold heritage data and will articulate processes. As a result, a simple and visual HBIM protocol was developed and applied in a real case study. The protocol was named BIMlegacy and it is divided into eight phases: building registration, determine intervention options, develop design for intervention, planning the physical intervention, physical intervention, handover, maintenance and culture dissemination. It contemplates all the stakeholders involved.
\end{abstract}

Keywords: BIM; HBIM; heritage architecture; protocol; management; cultural heritage

\section{Introduction}

\subsection{Existing Buildings and Heritage Buildings}

According to Historical England and the Department for Communities and Local Government of United Kingdom [1] the definition of Heritage assets is: "A building, monument, site, place, area or landscape identified as having a degree of significance meriting consideration in planning decisions, because of its heritage interest."

Historic buildings and sites should be preserved as cultural legacy and common heritage [2]. The Charter of Krakow [3] is the most recent document defining the principles for conservation and restoration of built heritage. There are categories among the existing buildings and sites depending on its cultural values, antiquity or artistic importance. They are categorised depending on the country or state; generally, they include common recent existing buildings, catalogued buildings with protected 
areas and heritage buildings that are clearly protected [4]. This research focuses on private medium size protected buildings. The difference between common existing buildings and heritage ones is that heritage projects involve architectural, historic and archaeological documentation, so it involves the technical reproduction of a context, as well as an intellectual effort to describe the socio-cultural heritage setting [3].

\subsection{Main Issues in Managing Heritage Buildings Interventions and Need for a Solution}

There are significant inefficiencies on heritage architecture interventions-conservation, rehabilitation restoration and reconstruction. These inefficiencies tend to compromise the preservation of cultural heritage for sustainable economic development as it makes the conservation of heritage buildings costly. Furthermore, there is an increasing interest in the adoption of new methodologies by heritage organisations and work groups, aiming to improve those inefficiencies $[5,6]$.

Many stakeholders, with a variety of backgrounds, are involved in heritage intervention projects for example, archaeologist, archivist, structural engineer and restorer [7]. These stakeholders usually work separately, so dispersed data is produced [8], sometimes duplicating work or not taking into consideration existing information or other stakeholders' contributions [9]. For example, the architect may research the history of the building without considering the archivist or historian's work previously generated.

The use of unconnected protocols and divergent techniques contribute to this dispersion of information. Modern technologies, such as 3D systems and laser scanning for surveys, are occasionally used in heritage buildings. However, these tend to be used just to support specific tasks and in many instances, these are unconnected with the general purpose of the project [10]. Furthermore, traditional methods and files are used, producing diverging data that hinders interoperability [11].

These ineffective work practices cause economic losses and the consequent distrust of historic project management [12]. As consequence, there are uncertainties in costs and schedules for property developers when developing a historic refurbishment or intervention [13].

Many international polices, as the Horizon 2020-European Commission, architectural regulations $[14,15]$ and different international conservation councils $[16,17]$ highlight the need for collaborative systems which enables better information sharing in heritage building projects. The same views are shared by researchers, for example, Dore and Murphy [18]; Brumana et al. [19]; Arayici et al. [20].

Hence, there is a need to develop solutions aimed at improving the management of heritage building projects. The need for such solutions is further highlighted by the fact that there is an increasing number of heritage buildings needing restoration work in cities across Europe [3]. Refurbishments, rehabilitations and other conservation interventions in existing buildings represent a high percentage in the total construction industry. For example, in Spain in 2016, refurbishments represented $55.7 \%$ of the total of construction sector according to the Ministry of Competitiveness. An increasing part of these refurbishments does focus on heritage buildings. Furthermore, cultural tourism is a great opportunity for sustainable economic development and well-preserved heritage buildings are fundamental to enable this.

\subsection{Research Objectives}

The aim of this research is to propose a Historic Business Information Modelling (HBIM) protocol to manage interventions in heritage buildings, including the diverse stakeholders involved in this process. The benefits of the adoption of such protocol by heritage stakeholders are that it provides clear guidance on how to adopt HBIM and highlights the human and material resources needed. The use of this protocol will support sharing of information, control of changes during the intervention project, the up-front accuracy of the project costs and the contemplation of all the life cycle stages of the building. 
The objectives are: (1) to study the stakeholders needs in heritage interventions and the real issues of HBIM application; (2) to design a protocol for managing the interventions in historical buildings with HBIM; and (3) to evaluate and validate the designed protocol with interdisciplinary professionals in a workshop and in a focus group.

In this research, managing historical building projects involves the recording of the existing historic building information, modelling the existing building and information, designing the intervention (e.g., refurbishment), developing construction works and planning the preservation of the monument. A multidisciplinary approach to the process is taken on this research.

\section{Literature Review}

\subsection{Business Information Modelling (BIM)}

ISO Standards defined BIM as "shared digital representation of physical and functional characteristics of any built object [ ... ] which forms a reliable basis for decisions" [21]. Recently, the UK government defined BIM as "a collaborative way of working, underpinned by the digital technologies which unlock more efficient methods of designing, delivering and maintaining physical built assets. BIM embeds key products and asset data in a 3D computer model that can be used for effective management of information throughout an assets lifecycle" [22]. BIM has evolved into a more open concept taking into account the lifecycle management of the buildings.

BIM has been successfully adopted in new buildings, supporting sustainable architecture [23,24], facilities and structures [25]. Nevertheless, the literature shows that processes and human resources related to BIM still need further study [26]. Research on BIM is becoming more specialised, for example examining the impacts of BIM maturity on project performance $[27,28]$. Various frameworks and protocols for collaborative design processes have been developed to facilitate BIM implementation [29].

\subsection{HBIM}

HBIM has been defined as the recording and modelling of existing buildings, generating BIM geometry from point clouds [30]. Murphy has defined HBIM as a new system of modelling historic structures creating full 2D and 3D models, which include detail behind the surface of the objects concerning its methods of construction and material makeup [31]. Recently, HBIM was also named Heritage Building Information Modelling, a broader term that includes historical data, conservation policies and significance values [17]. Heritage BIM includes highly protected buildings that usually requires broader intervention projects and a careful life cycle management. Dore and Murphy [30] proposed six HBIM elements: heritage documentation standards, data collection techniques, 3D modelling concepts, as-built BIM and procedural modelling.

The application of BIM to existing buildings is recent but there is an increasing interest in the area, especially for maintenance and large refurbishments [10]. However, these applications do not contemplate the historical and cultural legacy of the buildings and sites [32]. Volk [10] stated that BIM implementation in existing buildings is scarce, needing improvements in conversion point clouds to BIM models, updating data in BIM and modelling items and relations in existing structures.

\subsection{Potential Issues of HBIM}

The potential of BIM in the specific heritage context resides on:

- The capability to represent the historic phases in an integrated way [16].

- The intrinsic database that the computerised BIM systems have, which allows the synchronisation of information in real time [33].

- The creation of libraries of historic constructive items designed from historic manuscripts and architectural pattern books [15]. 
- The possibility structural and efficiency situations [34]. HBIM can help reduce errors since information can be updated in real time and different stakeholders work can be synchronised, reducing the potential of human error.

BIM has been originally designed to support new buildings. This could make BIM adoption to heritage buildings challenging due to the specific characteristics of historic buildings [35]. For example, they have an extended time of use that usually alters some of their features: repurposed structures, reused materials and shape variations. Historic buildings usually include a diversity of fabrics, several historic-constructive phases and sometimes pathologies such as cracks or humidity [36]. Heritage stakeholders have different needs than those of regular Architecture, Engineering and Construction (AEC) professionals and these needs to be considered [37].

\subsection{Existing HBIM Protocols, Methods or Guides}

Different HBIM guides and protocols have been proposed in the literature. These are briefly summarised below.

In 2012, the Royal Institute of British Architects (RIBA), published the RIBA outline plan of work including BIM, its levels of maturity and discussing its challenges. In 2013, the Construction Industry Council published a BIM protocol with eight structured phases as a response to the UK Government BIM Strategy [38]. It included definitions, Levels of Development (LOD), contract BIM statements and a relation between the stakeholders and the phases of the protocol. Both documents focus on supporting the adoption of BIM in new buildings.

The Conference on Training Architectural Conservation (COTAC) Report, 2014, summarised the outcomes of the three annual COTAC Conferences in relation to HBIM [39]. It uses the CIC diagram and overlaid the ICOMOS Education and Training Guidelines, as described in Figure 1. This model was further developed with the support of 5 international heritage organisations in 2016 [16].

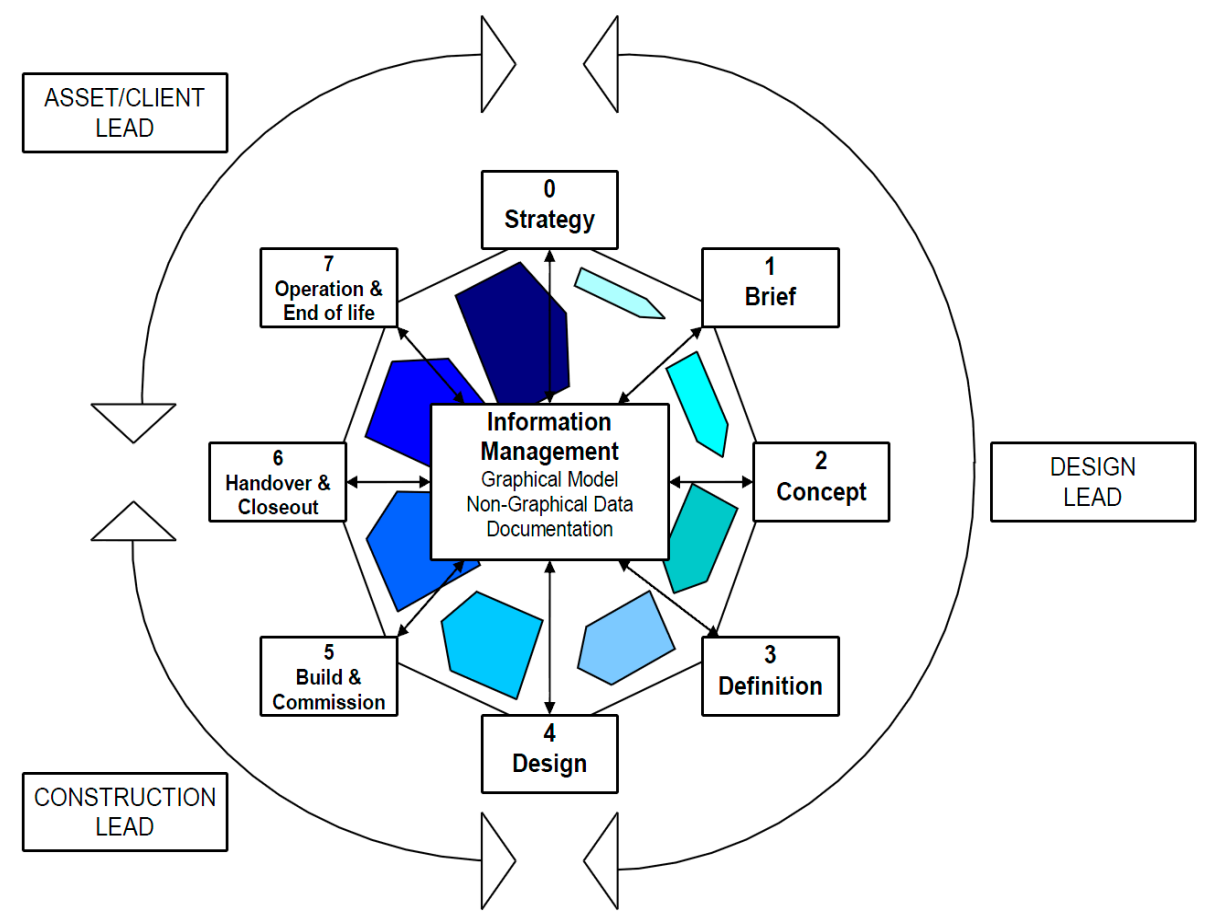

Figure 1. Construction Industry Council (CIC) Building Information Modelling (BIM) Cyclical Diagram.

The COTAC Report, 2016, compiled heritage principles with the CIC diagram and creates the COTAC HBIM Cyclical Diagram [16]. It took five relevant heritage organisations, synthetize their principles and overlapped them with the CIC diagrammatic framework. This five organizations where: 
the ICOMOS Education and Training Guidelines, the BS7918: 2013 Guide to conservation of historic buildings, the application of Historic England Conservation Principles Policies and Guidance of 2008, UNESCO Disaster Risks Management Cycle and the previous COTAC diagram generated in 2014.

The AEC (UK) BIM Technology Protocol [22], launched in 2015, is aligned with the PAS 1192-2:2013 [26] and provides BIM standards and specific guidance for diverse modelling software. In the Spanish context, The Building Smart Spanish Chapter [40] developed the u-BIM guides in 2014 to help BIM adoption for diverse purposes for example, facilities management, design, energy consumption. This includes one section dedicated to existing buildings. Recently, the Building Smart Spanish Chapter has created the HBIM commission to adapt HBIM to the needs of Spanish heritage projects. Some authors of this paper are active members of this group.

In the UK context, Historic England published "BIM for Heritage" in 2017 to guide owners, end-users and professionals to develop Historic Building Information models [14]. It defines what HBIM is, its benefits, how to manage BIM data, how to commission HBIM and describes interesting cases in which HBIM was used. It proposes a life cycle principle, depicted in Figure 2, with different phases. One important contribution of this guide is the definition of LOD in HBIM, which was not addressed in previous protocols.

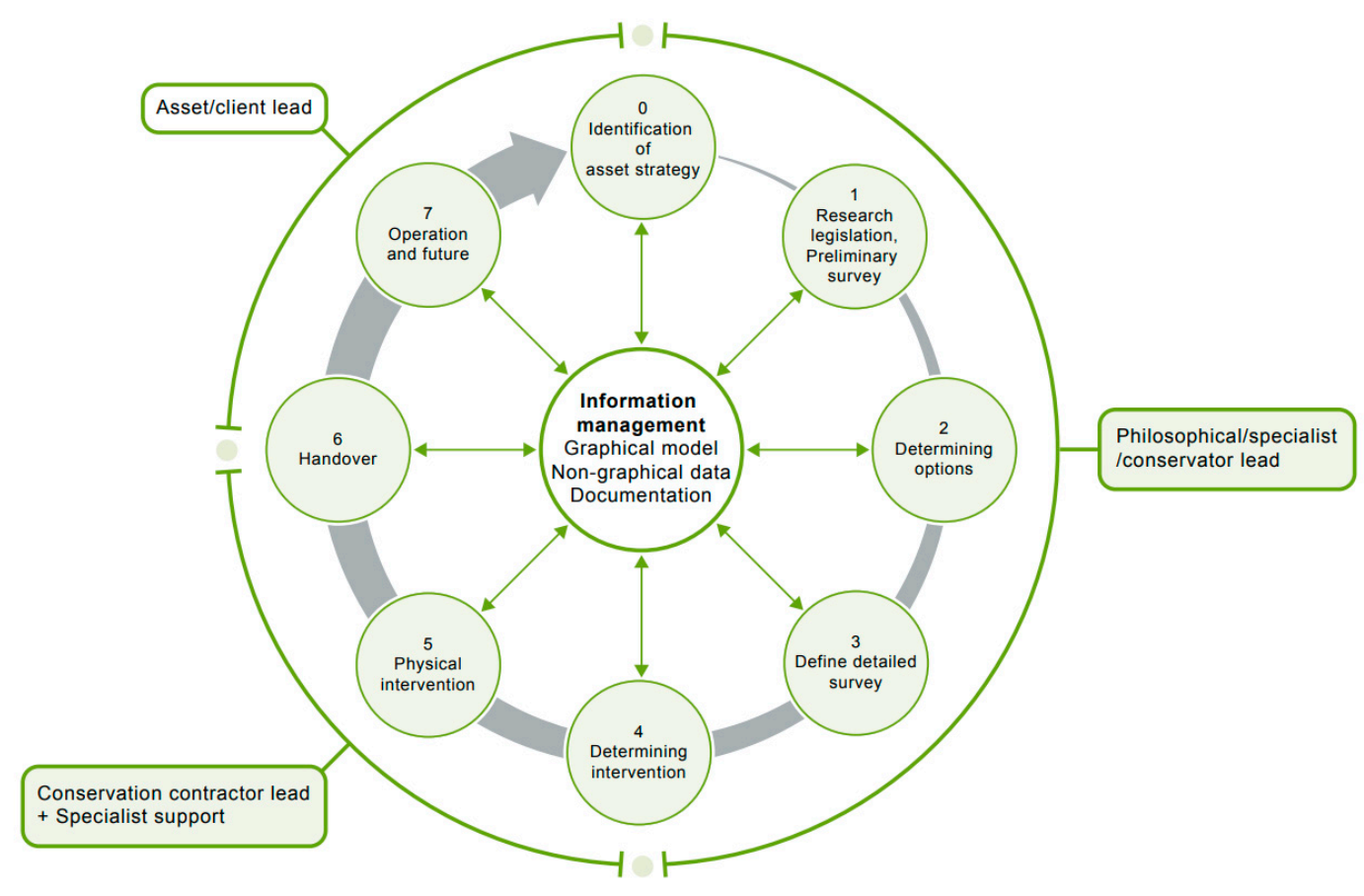

Figure 2. BIM for the Heritage Life Cyclical Principle.

There are also guidelines available on heritage intervention practices. For instance, International Restoration Charters created different documents describing good intervention practices and methods. Different heritage organisations, such as Heritage England or the Instituto del Patrimonio Cultural de España (IPCE), had been updating their interventions guides, creating specific heritage guides for particular heritage types (i.e., industrial, religious, defensive) and proposing laws (Law of Spanish Legacy) [41]. Also, architects such as Moreno-Navarro [42] designed their own heritage project methodologies, defining the phases of the intervention project as follows: (1) previous studies; (2) intervention objectives; (3) architectonic project; (4) construction; and (5) intervention diffusion.

In terms of protocols connecting Restoration with BIM, Megahed [35] developed an initial theoretical framework explaining the different aspects of historic preservation and management. A Metric Survey Specification was created defining the different steps of a heritage survey using 
different techniques, including HBIM [43]. During a workshop held in Luxor, Egypt, Counsell [44] proposed a cloud-based workflow for analysing best practices to 3D point clouds.

The existing HBIM protocols and guides present efforts to link conservation principles with BIM technologies. However, HBIM is still an emerging area and further research is needed in identifying specific stakeholder's needs, better aligning these with traditional heritage procedures and evaluating these through practical implementations of HBIM.

\section{Research Method}

Design Science Research (DSR) is the approach adopted for this research. DSR focuses on solving practical problems with theoretical relevance and producing artefacts as an output [45]. As this research focuses on solving a practical problem, that is, supporting the use of BIM in heritage buildings and involves the design of an artefact (the BIMlegacy protocol), DSR was considered the most appropriate approach to undertake the research. Figure 3 represents the research design adopted, which is iterative in nature.

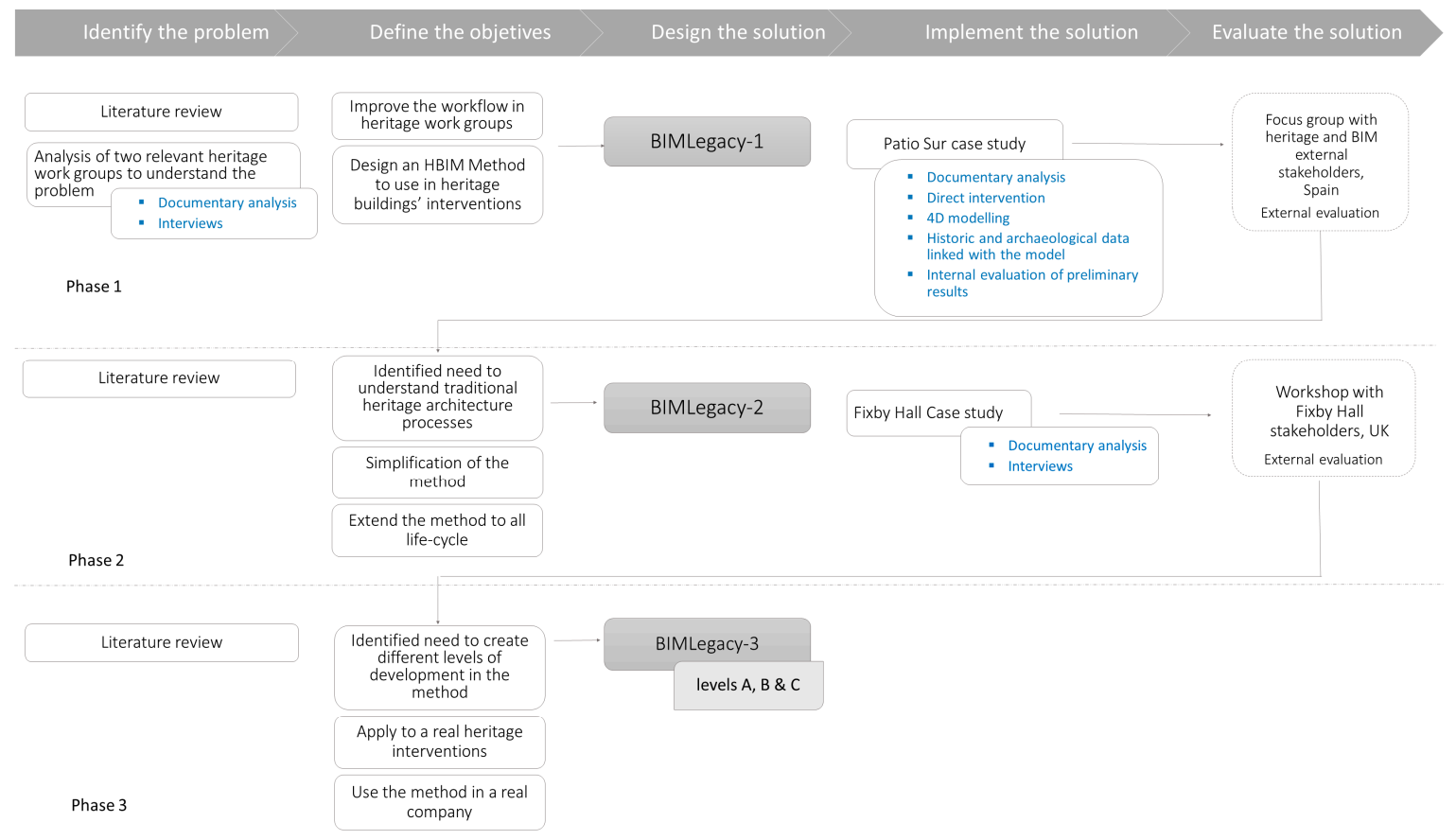

Figure 3. Research design.

The research was divided into five stages: identify the problem, define objectives, design the solution, implement the solution and evaluate the solution, as proposed by Peffers, Tuunanen, Rothenberger, \& Chatterjee [46]. The investigation included three iterative phases.

The artefact, named BIMlegacy protocol, was designed and evaluated in different cycles in two heritage projects: (1) Patio Sur of San Juan del Hospital, a gothic cemetery in Valencia, focusing in the BIM modelling, (2) Fixby Hall Gregorian building. Those projects were chosen as case studies because of their heritage richness, complex geometries and the researchers' access to the involved stakeholders. The three research phases are described as follows.

\subsection{Phase 1}

The research problem was initially identified through a review of the literature. In order to understand the practical problem in-depth and the challenges of HBIM adoption, five unstructured interviews with heritage stakeholders, two site visits to successful and document analysis (e.g., design drawings, technological implementation plans) were done. The visited monuments were the Sagrada 
Familia Temple [47] and Santa María of Vitoria Cathedral in order to know their departments and how they manage their construction works. The interviewed stakeholders were: (a) architect (13 years of experience); (b) construction manager (8 years), technical architect (18 years), archivist (25 years), topographical surveyor (22 years) and heritage diffusion expert (12 years). The questions asked included: What departments are involved in managing your monument? Which stakeholders are involved? How do you archive the produced information? The results obtained included an organizational chart of both monuments, a list of stakeholders and a list of initial requirements to implement HBIM.

The results of the heritage specialists' interviews, the literature review and document analysis were organized into overlapping flowcharts. For example, Figure 4 was generated to present The Sagrada Familia processes flowchart-obtained from the document analysis—with HBIM concepts from the literature. Some of the HBIM concepts included were for example building record using laser scanning, the representation of constructive phases, the collaboration different stakeholders and the creation of tender documentation from the HBIM model.

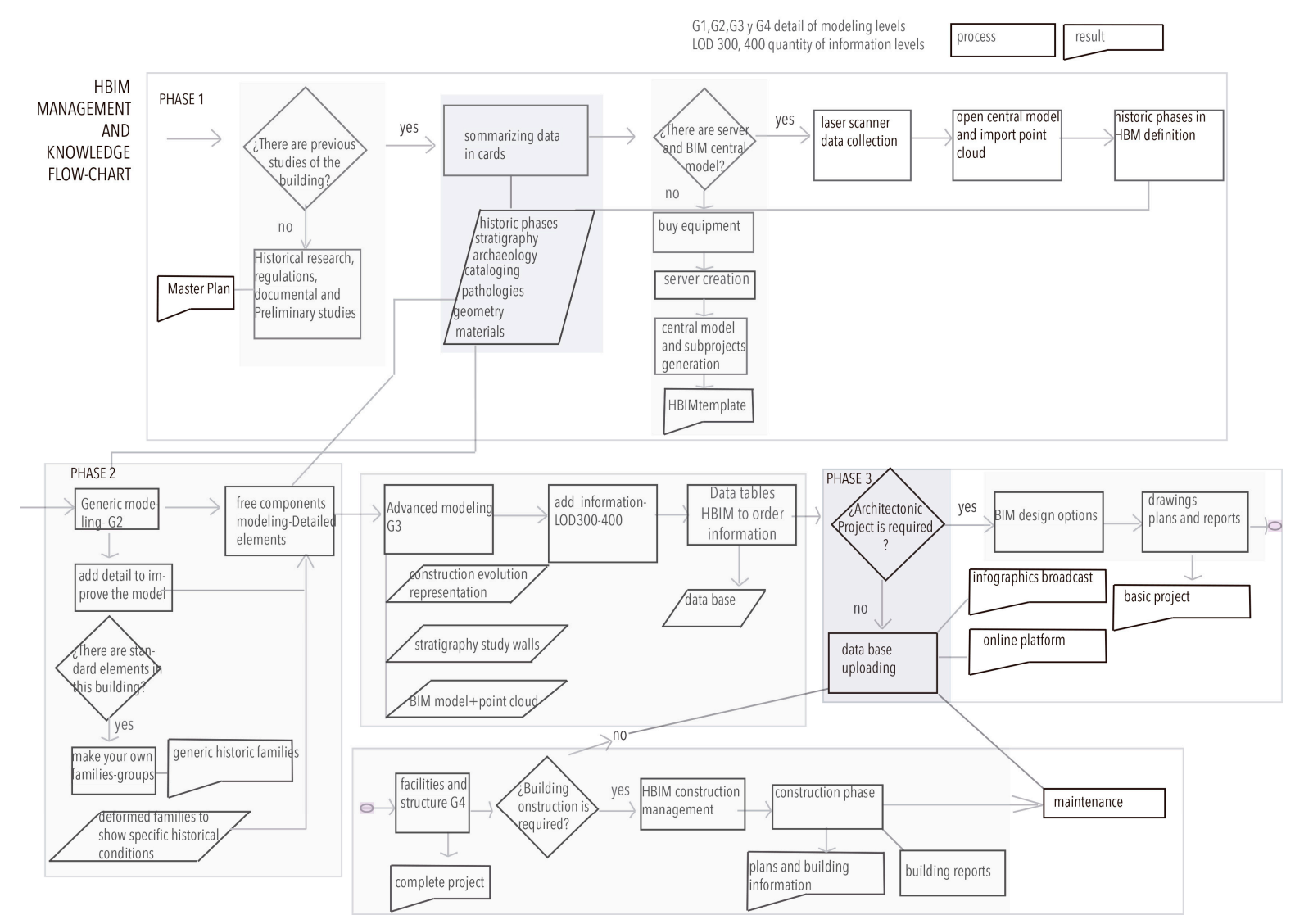

Figure 4. Research work chart used during the design process to overlap the Sagrada Familia processes flowchart with Heritage Building Information Building Modelling (HBIM) concepts obtained in the literature review.

This first version of the artefact was applied to the Patio Sur gothic cemetery, as shown in Figure 5. A laser scanning survey and a 3D modelling of this heritage asset was done using Revit Autodesk 2016. The conversion of the point cloud into a geometrical 3D model was done with Cyclone plug in for Revit and manually modelling over the point cloud, since the plug in just recognised flat surfaces. Thus, the scan to BIM process was semi-automatic. Four sub models, divided through disciplines-architecture, archaeology, structure and mechanical and electric systems (M\&E) — created a central model hosted on an online platform. They facilitated the collaborative work for four stakeholders. Libraries and Revit 
families were created both external and internal. The repetitive elements, such as the characteristic gothic arc, were standardised in external parametrised families based on geometrical parameters. The complex elements, such as sculptures, were created with 3D nets and imported into Revit. Five previous historical phases were also modelled but with lower LOD since there were not enough information to recreate how the building was in ancient times with a lot of detailing. The general LOD of the model was 300 taking into account geometrical modelling and quantity of information. Historic and archaeological information was introduced through a plug-in prototype that allows the synchronisation of historians and archaeologists.
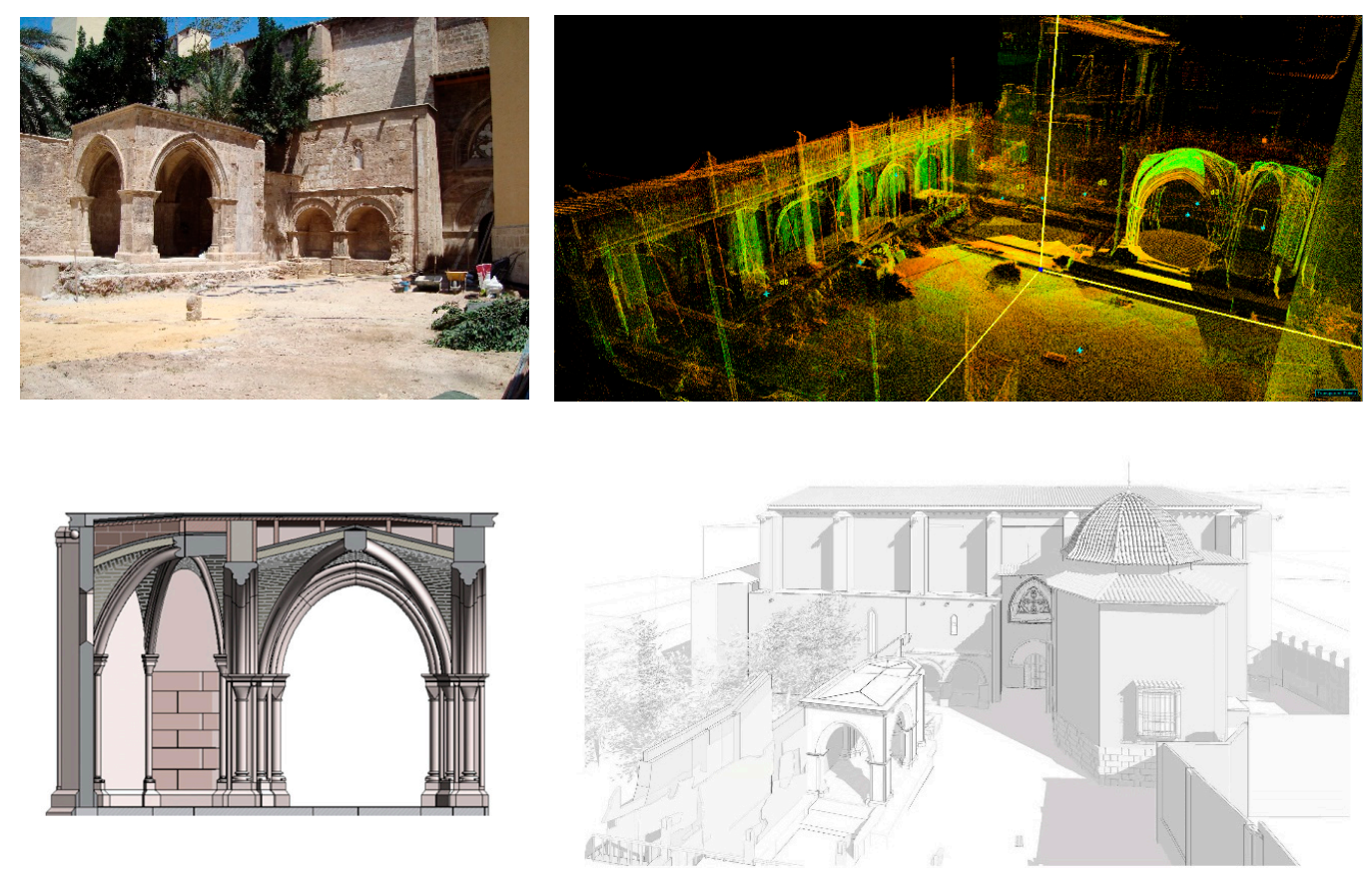

Figure 5. The modelling results of the application of HBIM modelling to the Patio Sur.

This practical demonstration assisted to refine the protocol by understanding the difficulties of HBIM modelling and the heritage stakeholders' needs.

BIMlegacy-1 was presented in a focus group in order to evaluate its effectiveness and efficiency. The BIMlegacy protocol and the results of its application to the gothic cemetery were discussed. Focus group participants included a BIM consultant (6 years of experience); a BIM university professor with knowledge in heritage architecture (18 years); a BIM specialist who is a construction engineer (4 years); a BIM architect with experience in heritage (25 years); and a planning consultant who uses BIM (10 years). Some of the discussions included: "Which difficulties do you find in modelling historical buildings after seeing the results of this case study?", "Do you think that the case study was documented in an appropriate way?", "Do you think BIMlegacy-1 is effective?" The results obtained from this focus group were that BIMlegacy-1 needed to improve the historical documentation process linked with the HBIM models, the definition of the archaeologist' modelling tasks and the representation of heritage buildings pathologies.

\subsection{Phase 2}

The results from the application of BIMLegacy version 1 and the recommendations from the focus group were used to improve the protocol. The redesigned artefact was BIMlegacy version 2 . The Fixby Hall case study was developed to obtain further information about traditional work processes (in a context outside Spain) and to make the protocol more user-friendly. This historic listed building is located in Huddersfield, UK and it is used as golf club headquarters. 
Firstly, building data was collected consisting of a general comprehension of the building, identification of the stakeholders and companies involved, one site visit, a photographic report and analysis of old architectural designs of the building. This phase also involved the identification of relevant historic and architectural documents, the research of diverse stakeholders' archives and the study of the 125-anniversary book of Huddersfield Golf Club [48].

Seven one hour semi-structured interviews were developed with: (a) the property, a real state charter surveyor (26 years of experience); (b) the monument manager (8 years); (c) the maintenance manager (28 years); (d) the archivist (12 years); (e) the heritage outreach manager (9 years); (f) the interior architect (7 years); and (g) the contractor (12 years), who were involved in previous refurbishment projects in Fixby Hall. Questions included: "In the case that a refurbishment of Fixby Hall was needed, what type of procurement is likely to be adopted?", "what would be your involvement?" The questions aimed to identify stakeholders, traditional processes and possible issues related with HBIM implementation.

This case study assisted to build the protocol by identifying further stakeholders, not discussed in the literature, linking traditional processes with HBIM processes and identifying possible issues related to HBIM practical implementation. Some important heritage processes, such the archaeology report relationship with the HBIM phases and the great variety of stakeholder's background, are examples of findings through this case study.

In the evaluation stage, the BIMlegacy-2 was presented at an interdisciplinary workshop with the main stakeholders involved with Fixby Hall. This one-hour and a half workshop included the owner of the building who is also a charter surveyor (26 years of experience), the HGC director (8 years), the architect specialised in BIM (20 years), the planning consultant specialised in heritage (22 years) and the BIM consultant (3 years). These stakeholders evaluated the stages and activities of BIMlegacy and proposed possible improvements.

\subsection{Phase 3}

BIMlegacy version 3, which is presented in this paper, was designed taken into account the knowledge achieved through the Fixby Hall case study and the evaluation resulting from the workshop. A new workflow was created synthetizing the issues pointed out in the evaluative workshop. The protocol was simplified, to make it more useful and less dense to understand, it was also made more flexible to different scales and resources and its scope was increased to include the whole life-cycle of the building.

\section{Results}

\subsection{BIMlegacy Protocol}

BIMlegacy, shown in Figure 6, is an overall protocol aimed to support the adoption of HBIM in heritage interventions. It was developed on the basis of the CIC BIM Cyclical Diagram, Construction Industry Council, [14], as well as on the results of the primary data collected throughout the research.

It includes three development layers-A, B and C - and each layer has a higher level of detail. BIMlegacy was divided into eight chronological phases. Layer A was designed to be clearly understandable by all stakeholders (see Figure 6) and layer B (Figure 7) contains all the steps of each phase of the life cycle. It describes all the phases of the protocol and its structure is circular, having in the centre the BIM model and the BIM Platform. BIMlegacy proposes that the intervention information should be hosted online, as heritage stakeholders usually do not work in the same physical space. The communication between the HBIM models and the historians and archaeologists' databases were designed to be unified in real time. In this online space, stakeholders have a workspace to share data. 


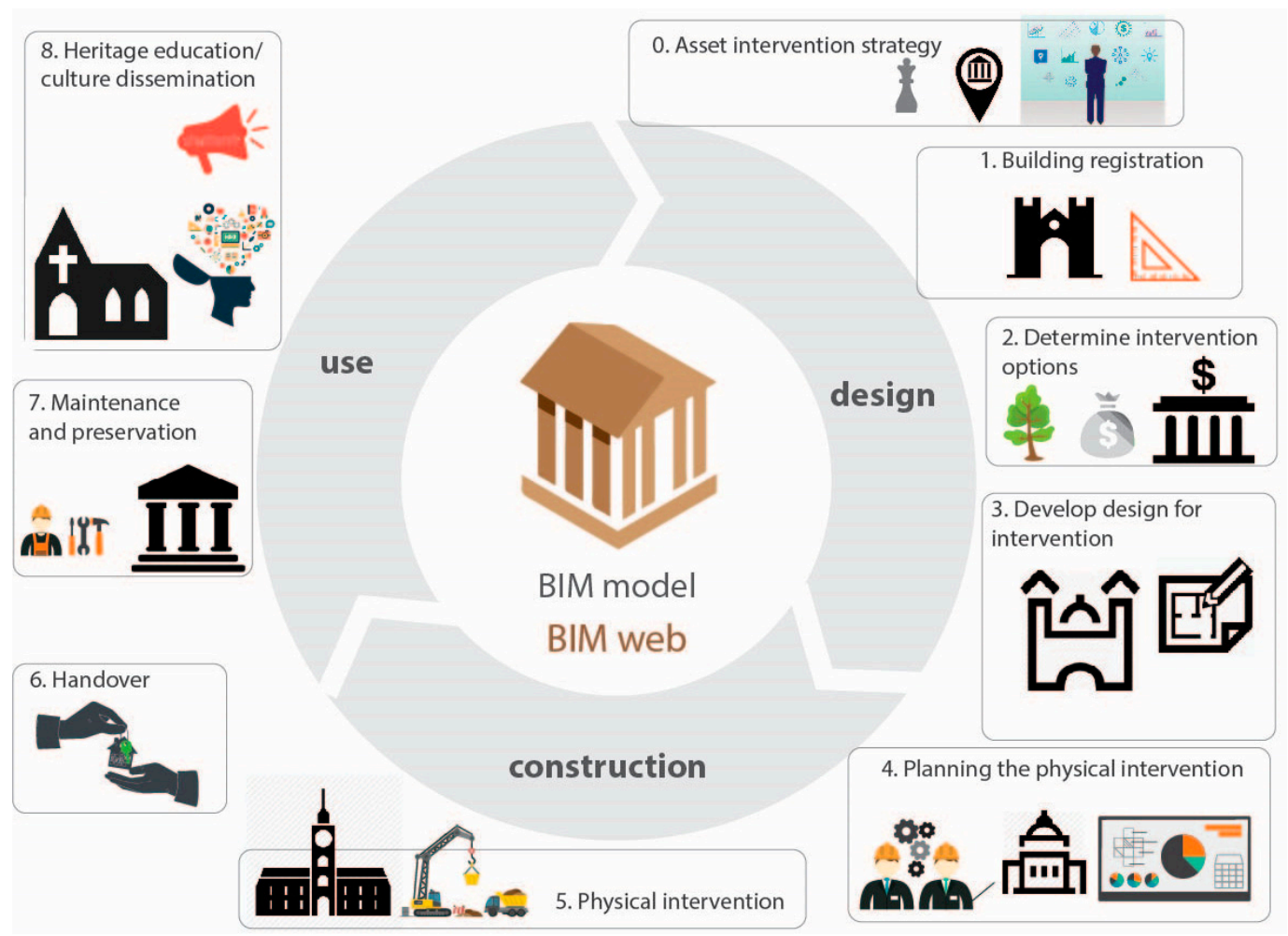

Figure 6. BIMlegacy-3, layer A, HBIM overview.

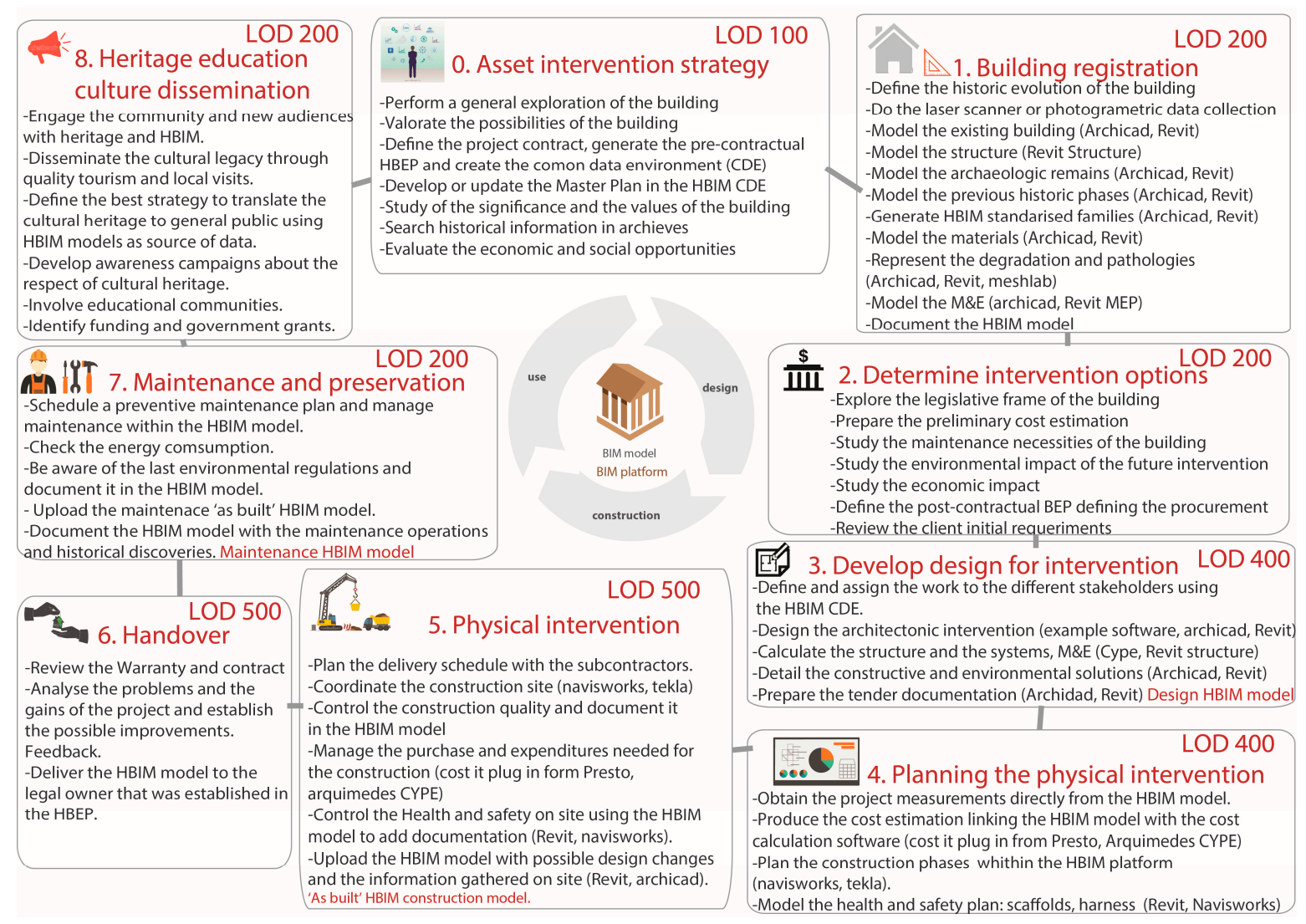

Figure 7. BIMlegacy-3, layer B. 
Layer B consists of eight pages, each of which describes the different phases of the process. It is also designed to be clearly understandable by both technical and non-technical stakeholders. It describes who should participate and who leads the phase and there is a tasks-list with a short description of each one.

Layer $C$ will be developed in future research work. It will include a modelling protocol and HBIM guides with specific explanations for each of the eight phases. Its focus will be to support the technical teams leading each phase. It will include, for example, instructions on how to model different historical phases in a single file, guides on how to build a HBIM model from a point cloud and how to parameterise historical construction items such as pointy arcs.

BIMlegacy also proposes specific training for heritage stakeholders: owner, planning consultant, chartered surveyor, historian, archaeologist, monument manager, planning officer prior, architect, engineers, contractor, suppliers, construction manager, construction workers and restorer. It is known that architects, engineers and construction companies are starting to use BIM [49]. However, heritage stakeholders have in general poor BIM knowledge, so those projects cannot yet achieve the intended benefits from BIM. Specifically, the non-designer stakeholders require training to understand the technology potential in order to start to develop their activities in a HBIM environment. It is believed that this will represent a great improvement in the heritage production chain. This concept could be named "HBIM for the property." As building owners have no previous technical knowledge, HBIM for the property needs to be as much user-friendly as possible. So, the online platform proposed in this research where non-technical stakeholder will communicate with the HBIM models were considered in the case studies to be very useful due to its visual interfaces and simplicity.

BIMlegacy online platform permits data unification in real time and independently from the stakeholders' location. This platform performs as a database server, as well as a workspace for stakeholders who do not model in 3D (i.e., property, archivist, planning consultant, monument manager). All data should be held in the online server; nevertheless, access permissions could be applied to the different folders.

\subsection{Description of the Phases}

Layer B of BIMlegacy consists of the eight phases presented below in a summary diagram (see Figure 7). These phases are comparable with life-cycle management methods such as RIBA Outline Plan of Work [50] and Building Smart Spanish Chapter [36]. The differences between BIMlegacy and previous protocols (Figures 1 and 2) are:

- It includes the breakdown of each phase, which previous protocols, Figures 1 and 2, did not have.

- It provides the indicative LOD that each phase should has.

- It includes specific processes of the interventions in historical buildings, such as the representation of pathologies in phase 1, the definition of the historical evolution of the building in phase 1 and the engage of the community with heritage using HBIM as graphical resource in phase 8 .

- It modifies some standardised BIM tasks in order to adapt these to Historic Architecture activities. For example: the modelling of archaeological remains and the inclusion of heritage values within the HBIM model parameters.

- It also includes specific stakeholders such as the restorer, the archaeologist, the charter surveyor, or the archivist and their relationships with the HBIM procedures.

Each of the phases is briefly described as follows. The extended descriptions and figures are presented in Supplementary File.

Phase 0. Asset intervention strategy. This includes the first evaluation of the condition of the building, the creation of the pre-contractual Historical BIM Execution Plan (HBEP) and the potential values of the building in terms of culture dissemination. The strategy phase is more extensive than in regular projects because heritage buildings usually require detailed previous studies of the architectonic, historic and archaeological values of the building [3]. Furthermore, the establishment 
of a Common Data Environment (CDE) is key to enable data sharing throughout the intervention project. The level of development (LOD) recommended is LOD 100 and just an initial HBIM model with masses is helpful since it is just required to obtain general measurements and to archive the initial information. The need for an intervention strategy was stablished with the basis of existing protocols (e.g., COTAC, 2016). Such need was also validated by the stakeholders from the Fixby Hall case study. BIMlegacy describes all the stages of a heritage building intervention; nevertheless, not all projects will require such detailed modelling and the needs for each project should be defined at the beginning of the process, according to the strategic objectives of the client and project team abilities with BIM. The purpose of adopting HBIM at each specific project should be defined in phase 0 .

Phase 1. Building registration is the architectonic survey and the link of all the historical, archaeological and city planning information. The 3D modelling takes the point cloud from laser scanner as a skeleton to start the model. The HBIM modelling of the building includes the generation of HBIM materials and constructive details libraries as well as HBIM families with the specific and repetitive stylistic elements. This phase also contemplates the definition of its historic evolution with specific guidance for the LOD of the different constructive hypothesis. For example, it is required to model the XII century phase in a church but there is not enough information to model it with LOD300. This guidance indicates you how to model it and with how much detail depending on the existing information. Modelling the current degradation condition of the building embraces the representation of pathologies, the archaeological remains registration, the stratigraphic studies representation if necessary and the artistic sculptures modelling. In addition, if the original designs are available, the M\&E modelling and the structure should be represented. The building registration has at least LOD 200 but the modelling of the existing condition should have a LOD 300 level of detail since the point cloud provides accurate information and it is the more relevant construction phase.

Phase 2. Determining intervention options of the possible refurbishment, restoration or conservation of the building that entails an overall evaluation of the building and/or site. The definition of the intervention criteria considers both design and construction criteria, for example the type of concrete to be used or the decision to excavate foundations manually. BIMlegacy plays the role of unifying information in this phase and enabling the stakeholder's functional communication. The LOD should continue in LOD 200 for previous phases and LOD 300 for existing phase.

Phase 3. Developing design for intervention includes the conservation, restoration or refurbishment project itself and its documentation. Designs will be developed using 3D models as base to produce the intervention project. Different stakeholders will work with the 3D models. Architects, archaeologist and construction engineers would develop separate models which will be merged for quality checking. HBIM Energy consumptions 4D simulations should be performed in this phase to ensure the right sustainability behaviour of the heritage building. At the end of the phase a design HBIM model with a LOD 400 should be produced.

Phases 1 to 3 were established with the experience achieved performing the Patio Sur case study and completing it with the existing literature review. Then, these steps were validated and completed in the focus group with heritage professionals.

Phase 4. Planning the physical intervention (construction works). This scheduling has to consider specific regulations of the restoration field and it has to take into account uncertainties of an ancient building (e.g., unexpected structural damages, humidity in internal surfaces). The construction stakeholders in collaboration with the design and property stakeholders would lead this phase. HBIM will be used to develop a 4D 'as-built' construction model with a LOD 500. Every HBIM element will be linked with its real cost item within specific software for construction cost calculation. The construction plan is developed in specific 4D BIM software. Clash detection should be performed in this phase to reduce conflicts during the building intervention.

Phase 5. Physical intervention. Historical buildings usually need specific materials and constructive techniques in order to respect their integrity and to avoid producing unwanted chemical 
reactions [3]. During this phase, an as-built HBIM model will be developed, based on information collected during construction. The LOD should be 500 in order to provide the necessary level of detail.

Phase 6. Handover. It addresses the warranty and contract review and allows the team to meet and learn from decisions, to expose the intervention problems and discuss solutions for further projects. The transparency promoted through BIMlegacy facilitates the understanding of the stakeholders' issues. For example, all stakeholders could check the HBIM final construction model to see the final measurements. The technical stakeholders would access the HBIM model through BIM architectonic and engineering software while non-technical stakeholders would access it through the online platform and its simple viewer. At the end of this phase the HBIM model 'as-built' should be delivered to the legal owner, who was previously defined in the HBEP.

Phases 4 to 6 included elements that were designed with the experience achieved from the Fixby Hall case study, specifically with their last refurbishment. Then, these steps were completed with the analysis of similar case studies in the literature and evaluated with the stakeholders who participate in the workshop.

Phase 7. Maintenance. Historic buildings require special attention to maintain their facilities and to preserve their cultural and artistic values. The 'as-built' model is a fundamental aspect in HBIM maintenance but the research results show that maintenance managers of historic buildings demand a simple system to control maintenance. Thus, incorporating maintenance information to the HBIM model and linking it to the specific management system that the property uses are essential. If the 'as-built model' is too complex or it has too much information, it will not be useful for maintenance managers.

Phase 8 . Heritage education. Heritage buildings usually have a rich history that makes them suitable as iconic community locations or touristic sites. BIMlegacy proposes that this kind of uses demand certain management systems related with the public visit control, the divulgation of the cultural values of the building within the community and the positioning as cultural site. This phase contemplates the integration of those intrinsic heritage processes within BIMlegacy. It proposes to use HBIM models as source of data to better explain the architecture legacy to the potential visitors.

Phases 7 and 8 included steps that were established after analysing the maintenance and heritage dissemination of all the monuments analysed in this research. These elements were validated in the workshop performed in the Fixby Hall case study.

\section{Discussion}

This paper presents a protocol named BIMLegacy aimed to help heritage stakeholders involved in medium size building interventions. It focuses on buildings owned by private institutions and underlines the possible benefits and issues of HBIM. These are discussed as follows:

\subsection{Benefits for Heritage Groups to Implement BIMlegacy}

Heritage architectonic representation requires a high level of detail in order to satisfy the cultural documentation and drawing principles [3]. The automatic updating of drawing views together with the creation of HBIM families and libraries undoubtedly helps the quality of heritage projects [51]. According to this research, achieving a quality HBIM model is very time consuming. BIMLegacy includes modelling recommendations to accelerate HBIM modelling and it establishes clear LOD for each phase. Detailed modelling provides the modeller with great knowledge of the building. For example, when modelling a gothic vault the modeller is forced to learn its metric rules. Standardization and heritage BIM libraries were not considered as relevant for the protocol success as previous literature indicates [15] because in heritage architecture diverse elements will have their own particularities and so there are limitations in the potential of using standardised libraries of objects.

In accordance with Brumana [19] the representation of all historic phases in one single file allows the understanding of the building evolution but the LOD levels in HBIM were not defined yet, which makes difficult the right representation of historical phases. BIMlegacy establishes LOD depending on 
the quantity of information of each constructive hypothesis - usually historic phases are difficult to model due to the lack of knowledge about how the building looked like time ago. The representation of ancient historical phases is fundamental to document the heritage building. In addition, historic phases have a great potential for the cultural dissemination according to the research results.

Past HBIM studies discussed the potential of common data environments and recommended their further study for heritage architecture [27]. The research participants recognised the innovative online platform of BIMlegacy as key factor for the success of the protocol.

The literature further states the need to include traditional heritage stakeholders and processes as part of the BIM workflow [52]. BIMlegacy includes traditional heritage workflows and synchronizes stakeholders' activities with the HBIM models through the proposed online platform, supporting their active participation in the intervention. This was also highlighted as a benefit of BIMLegacy by the research interviewees.

The unification of information in the HBIM models and clash detection have the potential to reduce rework and consequently the costs of heritage interventions, due to a reduction of errors which generally happen because of data dispersion [10]. Although the implementation of BIMlegacy may be costly initially, the project development times should reduce over time. The standardization of the work processes proposed in BIMlegacy supports the organisation of data and processes by heritage teams, which should provide economic benefits in the long term.

Heritage researchers like Megahed [39] highlighted the need of including non-technical professionals within BIM system. The simplicity of BIMlegacy, which was specifically designed to enable the process understanding by non-technical stakeholders, can aid decision taking. The visual online platform of BIMlegacy fosters collaboration between stakeholders in real time generating the creative conversation that is needed and facilitating that all the consultants can see each other's work; for example, the legal documents, the construction reports according to the workshop discussion. This was one of the conclusions of the workshop with the interdisciplinary stakeholders.

4D and 5D HBIM simulations have the potential to reduce conflicts and changes during construction and improve the accuracy of the construction budget, the constructability of the designed techniques and the energy consumption [32]. The designed protocol contributes to this by specifying modelling guidelines, including the LOD simulations and the requirements of the "as-built" heritage models.

Preservative maintenance information linked with the HBIM model improves the quality and accuracy of the operational systems in the building [53]. In this research, the results of the performed focus group demonstrate that maintenance models should be as simple as possible, containing only the necessary information for maintenance activities.

One of the main advantages highlighted in the literature for the use of HBIM is its ability to gather the documentation centrally [54]. However, this may lead to overloading the HBIM models with useless information and missing some stakeholder's data, according to the interviews analysis. BIMlegacy contemplates the holistic documentation of heritage interventions within the online platform linked with 3D models, which will be specifically designed for different purposes (e.g., a maintenance model, a historic documentation model). Furthermore, permission controls within the plug-in and online platform facilitates the non-duplication of information.

\subsection{BIMlegacy Issues}

Heritage stakeholders have in general poor BIM knowledge and HBIM adoption is still low according to both research participants and recent literature studies [55]. Thus, BIM legacy could be partially implemented, depending on the main goals of the heritage process and this should in turn support its wide adoption.

Research participants agreed that the point cloud technology is an exceptional technique to document the existing condition of a building. However, laser scanning has limitations regarding what is inside the fabrics due to the limitation for recording the interior composition of the walls [8]. 
Consequently, a building condition inspection to analyse the cohesion of the walls and the strength of the structure is still required. There will also be difficulties to access M\&E information, which may not be existent or registrable with laser scanner.

Different countries are adapting their construction legislative frames to BIM systems but it seems that they are having problems to achieve this aim [56]. Heritage constructions have extra legislative regulations to protect their cultural values and historic background. In the United Kingdom, the adoption of BIM by part of these bodies was supposed to be completed by now, according to the Government's Construction Strategy. However, the International BIM Report 2016 [57] shows that even though a positive attitude exists towards the fact that the Government is taking the lead on BIM, local and national institutions are not prepared yet for such a change.

\section{Conclusions}

BIMlegacy is a protocol for implementing HBIM in heritage buildings' interventions, contemplating the whole life cycle of the building or asset. It integrates BIM with the specificities of heritage buildings: the diversity of stakeholders and processes present this type of building, the exhaustive documentation required and the cultural values that need to be transmitted to the society. However, BIMlegacy needs to be applied to support the intervention process of further historic buildings, so it can be further refined and validated and measurable benefits and issues further identified.

\subsection{Research Contributions}

Historic buildings last centuries and the existing literature demonstrates the need for BIM based methods to support the management of heritage interventions [17]. This research proposes a holistic HBIM-protocol considering diverse stakeholders involved in historic architecture and contemplating the whole life cycle of the historic building.

Previous research underlined the need for considering traditional heritage processes in BIM environments [16,53]. BIMlegacy provides a contribution towards this need as it was designed on the basis of such traditional processes. It was also designed based on an in-depth identification of problems faced by heritage teams and perceived difficulties in adopting HBIM, more specifically difficulties related to the modelling processes.

The non-designer stakeholders require specific training to understand the technology potential; however, they should not be expected to use BIM software. Building owners, archivists, monument managers and government agents will provide inputs to the process, according to the non-technical interviewees.

Past research highlight concerns about the practical effectiveness of HBIM [10]. This research highlights that non-technical stakeholders require educational protocols in order to be active stakeholders within the HBIM models and platforms.

Finally, BIMlegacy has been devised to be simple and intuitive. Most existing protocols or guides are more complex and hence, arguably harder to implement in practice. Clear graphics and simple vocabulary are useful tools to make complex concepts understandable [24]. The contribution of this research resides in creating a simple and user friendly HBIM protocol, developed on the basis of previous literature as well as existing cases studies.

\subsection{Limitations and Future Research}

The limitations of this research reside in testing BIMlegacy with more real cases to further refine it. The research team plans to test BIMlegacy on the whole San Juan del Hospital historic site, located in Valencia, Spain. Some heritage stakeholders are sceptical regarding new technologies and this may negatively influence the implementation of the protocol. Detailed guidance for the implementation of BIMlegacy is needed. Modelling in this context requires considerable time, which could be seen as a 
limitation. Also, the legislative frame BIMlegacy is barely defined because HBIM laws or charts in different countries are inexistent.

The pathologies and the degradation representation is an important concern among the HBIM community since its modelling is exceedingly laborious [31]. However, a detailed HBIM modelling is included because it facilitates the understanding of the heritage building and helps to determinate correct intervention criteria. This may also impose limitations on BIMLegacy implementation.

Interventions on historic buildings usually are small-scale projects developed by small construction firms. Hence, there is a need to further understand how to implement BIMlegacy in such small firms.

Despite the efforts made in questioning the different stakeholders, the legislative body needs require further research [10]. The adoption of HBIM by Heritage Government Institutions may focus on the analysis of their human and material resources and their processes.

BIMlegacy proposes to control the renting and the furniture inventory through online platforms but this is a future line of study.

The HBIM education for non-technical stakeholders, such as building owners and construction workers needs further study following principles of usability and simplicity [24]. Modelling heritage items can be challenging, so innovative ways to represent sculptural, degraded or artistic elements with HBIM needs to be further researched [32,33]. According to BIM preservative maintenance recent studies [17], the "use" phases, that is, phase 7 and 8 of BIMlegacy protocol, require further study, especially in terms of preservative maintenance and heritage diffusion.

Supplementary Materials: The following are available online at http:/ /www.mdpi.com/2071-1050/10/3/908/s1, BIMlegacy protocol' phases. Extended descriptions and figures.

Acknowledgments: We would like to acknowledge the Spanish Ministry of Economy and Competitiveness for the support received to develop the project entitled: Design of a Database, Management Model for the Information and Knowledge of Architectural Heritage (HAR2013-41614-R), in kind support from the stakeholders involved. We would also like to thank the University of Huddersfield and the Universidad Politècnica de València for their support of this research.

Author Contributions: Isabel Jordán-Palomar generated the materials, performed the practical tasks and wrote the article as part of her PhD work, under the supervision of the remaining of authors. Patricia Tzortzopoulos designed the methodological approach; Jorge García-Valldecabres contributed theoretical materials and documentary sources; Eugenio Pellicer conceived the case study and its validation.

Conflicts of Interest: The authors declare no conflict of interest.

\section{References}

1. Department for Communities and Local Government of United Kingdom. Annex 2: Glossary, National Planning Policy Framework; Department for Communities and Local Government: London, UK, 2012.

2. Gazzola, P.; Leimare, R.; Bassegoda-Nonell, J.; Benavente, L.; Daifuku, H; De Vrieze, P.L.; Langberg, H.; Matteucci, M. International Charter for the Conservation and Restoration of Monuments and Sites; International Council on Monuments and Sites (ICOMOS): Venice, Italy, 1964.

3. De Naeyer, A.; Arroyo, S.; Blanco, J. Krakow Charter 2000: Principles for Conservation and Restoration of Built Heritage; Bureau Krakow: Krakow, Poland, 2000.

4. Eppich, R. Recording, Documentation, and Management for the Conservation of Heritage Places; The Getty Conservation Institute: Los Angeles, CA, USA, 2007.

5. Kempton, J. Can lean thinking apply to the repair and refurbishment of properties in the registered social landlord sector? Struct. Surv. 2006, 24, 201-211. [CrossRef]

6. Perng, Y.H.; Hsia, Y.P.; Lu, H.J. A Service Quality Improvement Dynamic Decision Support System for Refurbishment Contractors. Total Qual. Manag. Bus. Excell. 2007, 18, 731-749. [CrossRef]

7. Garagnani, S.; Gaucci, A.; Govi, E. ArchaeoBIM: Dallo scavo al Building Information Modeling di una struttura sepolta. Il caso del tempio tuscanico di Uni a Marzabotto. Archeol. Calcol. 2016, 27, 251-270. 
8. Gonzalez-Vares, I. Conservación de Bienes Culturales [Conservation of Cultural Items]; Manuales Arte Cátedra: Madrid, Spain, 2006; Chapter 10-11.

9. Migilinskas, D.V.; Popov, V.; Juocevicius, L. The benefits, obstacles and problems of practical BIM implementation. Procedia Eng. 2013, 57, 767-774. [CrossRef]

10. Xiong, B.; Adana, A.; Akincic, B.; Huberb, D. Automatic creation of semantically rich 3D building models from laser scanner data. Autom. Constr. 2013, 31, 325-337. [CrossRef]

11. Forster, A.; Kayan, B. Maintenance for historic buildings: A current perspective. Struct. Surv. 2009, 27, 210-229. [CrossRef]

12. Volk, R.; Stengel, J.; Schultmann, F. Building information modeling (BIM) for existing buildings-Literature review and future needs. Autom. Constr. 2014, 38, 109-127. [CrossRef]

13. Teo, M.; Loosemore, M. A theory of waste behaviour in the construction industry. Constr. Manag. Econ. 2001, 19, 741-751. [CrossRef]

14. Antonopoulou, S.; Bryan, P. Historic England 2017 BIM for Heritage: Developing a Historic Building Information; Historic England: Swindon, UK, 2017.

15. Construction Industry Council. Building Information Modelling (BIM) Protocol; Building Information Modelling Task Group: London, UK, 2013.

16. Maxwell, I. COTAC BIM4C Integrating HBIM Framework Report; COTAC: London, UK, 2016.

17. Spanish Ministry of Education, Culture and Sports. Plan Nacional de Abadias, Conventos y Monasterios [National Plan Forabbeys, Convents and Monasteries]; Spanish Government in collaboration with the Sacred Catholic Church: Madrid, Italy, 2004.

18. Dore, C.; Murphy, M. Integration of Historic Building Information Modeling (HBIM) and 3D GIS for recording and managing cultural heritage sites. In Proceedings of the 18th International Conference on Virtual Systems and Multimedia, Milan, Italy, 2-5 September 2012; pp. 369-376.

19. Brumana, R.; Oreni, D.; Raimondi, A.; Georgopoulos, A.; Bregianni, A. From survey to HBIM for documentation, dissemination and management of built heritage: The case study of St. Maria in Scariad' Intelvi. In Proceedings of the Digital Heritage International Congress (Digital Heritage), Marseille, Italy, 28 October-1 November 2013; pp. 497-504.

20. Arayici, Y.; Counsell, J.; Mahdjoubi, L.; Nagy, G.; Hawwās, S.; Dweidar, K. Heritage Building Information Modelling; Taylor \& Francis Group: New York, NY; Routledge: Abingdon, UK, 2017.

21. ISO Standard. Building Information Modelling_Information Delivery Manual_Part 1, Methodology and Format 2010; ISO 29481-1; ISO: Geneva, Switzerland, 2010.

22. AEC (UK) BIM Technology Protocol. Practical Implementation of BIM for the UK Architectural, Engineering and Construction (AEC) Industry; Version 2.1.1; The AEC Initiative: Jakarta, Indonesia, 2015.

23. Jeong, W.; Chang, S.; Son, J.; Yi, J. BIM-Integrated Construction Operation Simulation for Just-In-Time Production Management. Sustainability 2016, 8, 1106. [CrossRef]

24. Inyim, P.; River, J.; Zhu, Y. Integration of Building Information Modeling and Economic and Environmental Impact Analysis to Support Sustainable Building Design. J. Manag. Eng. 2015, 31, A4014002. [CrossRef]

25. Barnes, P.; Davies, N. BIM in Principle and in Practice; ICE Publishing: London, UK, 2014.

26. Sackey, E.; Tuuli, M.; Dainty, A. Sociotechnical systems approach to BIM implementation in a multidisciplinary construction context. J. Manag. Eng. 2015, 31, A4014005. [CrossRef]

27. Lee, J.; Jaejun, K. BIM-Based 4D Simulation to Improve Module Manufacturing Productivity for Sustainable Building Projects. Sustainability 2017, 9, 426. [CrossRef]

28. Smits, W.; Van Buiten, M.; Hartmann, T. Yield-to-BIM. Impacts of BIM maturity on project performance. Build. Res. Inf. 2017, 45, 336-346. [CrossRef]

29. Kassem, M.; Iqbal, N.; Kelly, G.; Lockley, S.; Dawood, N. Building Information Modelling: Protocols for collaborative design processes. J. Inf. Technol. Constr. 2014, 19, 126-149.

30. Dore, C. Murphy, M. Current State of the Art Historic Building Information Modelling; ISPRS: Paris, France, 2017; pp. 185-192.

31. Murphy, M.; McGovern, E.; Pavia, S. Historic building information modelling (HBIM). Struct. Surv. 2009, 27, 311-327. [CrossRef] 
32. Deniz, I.; Esin, E. BIM for building refurbishment and maintenance: Current status and research directions. Struct. Surv. 2015, 33, 228-256.

33. Quattrini, R.; Malinverni, E.S.; Clini, P.; Nespeca, R.; Orlietti, E. From TLS to HBIM. High Quality Semantically-Aware 3D Modeling of Complex Architecture; ISPRS: Paris, France, 2015; Volume XL-5/W4, pp. 367-374.

34. Oreni, D.; Brumana, R.; Della Torre, B.; Previtali, F. Survey turned into HBIM: The restoration and the work involved concerning the Basilica di Collemaggio after the earthquake (L'Aquila). In Proceedings of the SPRS Technical Commission V Symposium, Riva del Garda, Italy, 23-25 June 2014; pp. 267-273.

35. Barazzetti, L.; Banfi, F.; Brumana, R.; Gusmeroli, G.; Previtali, M.; Schiantarelli, G. Cloud-to-BIM-to-FEM: Structural simulation with accurate historic BIM from laser scans. Simul. Model. Pract. Theory 2015, 57, 71-87. [CrossRef]

36. Green, A.; Dixon, J. Standing buildings and built heritage. Post Med. Archaeol. 2016, 50, 121-133. [CrossRef]

37. Megahed, N. Towards a management. Theoretical framework for HBIM approach in historic preservation. Int. J. Archit. Res. 2015, 9, 130-147. [CrossRef]

38. Beale and Construction Industry Council (CIC). Building Information Model (BIM) Protocol. Standard Protocol for Use in Projects Using Building Information Models; Construction Industry Council: London, UK, 2013.

39. Maxwell, I. Integrating Digital Technologies in Support of Historic Building Information Modelling: BIM4Conservation (HBIM); COTAC: London, UK, 2014.

40. Cerdán, A.; González, J.; Mora, A.; Rodríguez, M. (Eds.) Guía de Usuarios BIM [BIM User's Guide]; BuildingSMART Spanish Chapter: Madrid, Spain, 2014.

41. Ley del Patrimonio Histórico Español [Law of Spanish Legacy]. Spanish Ministry of Presidency and Territory; BOE: Madrid, Spain, 1985.

42. Moreno-Navarro, A. Restoration of monuments, a specific methodology. Inf. Constr. 1998, 40, 397.

43. Andrews, D.; Bedford, J.; Bryan, P. Metric Survey Specifications for Cultural Heritage, 3rd ed.; Historic England: Swindon, UK, 2015.

44. Counsell, J.; Nagy, G. Participatory Sensing for Community Engagement with HBIM. Heritage Building Information Modelling; Routledge: Abingdon, UK; New York, NY, USA, 2017.

45. Holmström, J.; Ketokivi, M.; Hameri, A. Bridging Practice and Theory. A Design Science Approach. Decis. Sci. 2009, 40, 65-87. [CrossRef]

46. Peffers, K.; Tuunanen, T.; Rothenberger, M.A.; Chatterjee, S. A design science research methodology for information systems research. J. Manag. Inf. Syst. 2007, 24, 2007. [CrossRef]

47. Faulí, J. Composició I Continuïtat en les Columns I Voltes de les naus del Temple Expiatori de la Sagrada Família [Composition and Continuity in the Columns and Volts of the SagradaFamilia Expiatory Temple's Nave]. Ph.D. Thesis, Universitat Politècnica de Catalunya, Barcelona, Spain, 2009.

48. Smith, G. Huddersfield Golf Club, 125 Years at Fixby; Huddersfield Golf Club Ltd.: Huddersfield, UK, 2016.

49. Zhao, D.; McCoy, A.P.; Bulbul, T.; Fiori, C.; Nikkhoo, P. Building Collaborative Construction Skills through BIM-integrated Learning Environment. Int. J. Constr. Educ. Res. 2015, 11, 97-120. [CrossRef]

50. RIBA (Royal Institute of British Architects). Outline Plan of Work 2007; RIBA Publishing: London, UK, 2007.

51. Grover, R.; Froese, T.M. Knowledge Management in Construction Using a Socio BIM Platform. A Case Study of AYO Smart Home Project. Procedia Eng. 2016, 145, 1283-1290. [CrossRef]

52. Afsaria, K.; Eastman, C.; Shelden, D. Cloud-based BIM Data Transmission: Current Status and Challenges. In Proceedings of the International Symposium on Automation and Robotics in Construction, Auburn, AL, USA, 18-21 July 2016; Department of Construction Economics \& Property, Vilnius Gediminas Technical University: Vilnius, Lithuania, 2016.

53. Shingh, V.; Gu, N.; Wang, X. A theoretical framework of a BIM-based multi-disciplinary collaboration platform. Autom. Constr. 2011, 20, 134-144. [CrossRef]

54. Fai, S.; Graham, K.; Duckworth, T.; Wood, N.; Attar, R. Building Information Modelling and Heritage Documentation. In Proceedings of the XXIII International CIPA Symposium, Praga, Austria, 28 October-1 November 2013.

55. Dainty, A.; Leiringer, R.; Fernie, S.; Harty, C. BIM and the small construction firm: A critical perspective. Build. Res. Inf. 2017, 45, 696-709. [CrossRef] 
56. Gurevich, U.; Sacks, R.; Shrestha, P. BIM adoption by public facility agencies: Impacts on occupant value. Build. Res. Inf. 2017, 45, 610-630. [CrossRef]

57. Royal Institute of British Architects, RIBA (Ed.) NBS International BIM Report 2016; Attitudes towards Governments and BIM; RIBA Enterprises Ltd.: Newcastle upon Tyne, UK, 2016. 